\title{
Future changes in atmospheric rivers and extreme precipitation in Norway
}

\author{
Kirien Whan ${ }^{1} \cdot$ Jana Sillmann ${ }^{2} \cdot$ Nathalie Schaller $^{2} \cdot$ Rein Haarsma ${ }^{1}$
}

Received: 25 June 2019 / Accepted: 21 December 2019 / Published online: 28 January 2020

(c) The Author(s) 2020

\begin{abstract}
Flooding events associated with extreme precipitation have had large impacts in Norway. It is well known that these heavy precipitation events affecting Norway (and other parts of Europe) are strongly associated with atmospheric rivers (ARs). We assess trends in Norwegian AR characteristics, and the influence of AR variability on extreme precipitation in Norway. We first evaluate the ability of a high-resolution global climate model (EC-Earth) to simulate ARs, compared to ERA-Interim. We evaluate the EC-Earth simulated relationship between ARs and extreme precipitation in western Norway, compared to the observed relationship. We find that EC-Earth is able to simulate well the statistics of AR events and the related precipitation. The intensity and frequency of ARs making landfall in Norway both increase by the end of the century and we find a shift in seasonality of AR events in the future period. In two regions on the west coast, the majority of winter precipitation maxima are associated with AR events ( $>80 \%$ of cases). Next we assess the influence of AR variability on extreme precipitation. A non-stationary extreme value analysis indicates that the magnitude of extreme precipitation events in these regions is associated with AR intensity. Indeed, the 1-in-20 year extreme event is $17 \%$ larger when the AR-intensity is high, compared to when it is low. There is little influence of specific humidity on the variability of extreme precipitation after all variables are de-trended. Finally, we find that the region mean temperature during winter AR events increases in the future. In the future, when the climate is generally warmer, AR days will tend to make landfall when the temperature is above the freezing point. The partitioning of more precipitation as rain, rather than as snow, can have severe impacts on flooding and water resource management.
\end{abstract}

Keywords Atmospheric river $\cdot$ Extreme precipitation $\cdot$ Norway $\cdot$ Climate change $\cdot$ Global climate model $\cdot$ Extreme value theory

\section{Introduction}

Flooding can have large impacts on society and the economy (Kousky 2014). In Norway, flooding events have caused substantial damages. In 2005 for example, an extreme precipitation event in south-western Norway caused flooding and landslides that damaged property, injured many people, and caused the loss of one life (Stohl et al. 2008). This extreme event was linked to an atmospheric river (AR) (Stohl et al.

Kirien Whan

kirien.whan@knmi.nl

$1 \quad$ R\&D Weather and Climate Modeling, The Royal Netherlands Meteorological Institute (KNMI), De Bilt, The Netherlands

2 Center for International Climate and Environmental Research, Oslo, Norway
2008). In October 2014, flooding in Flåm and Odda was associated with an AR event (Langsholt et al. 2015; Schaller et al. 2019). Globally, ARs have been linked to extreme winds (Waliser and Guan 2017), storm surge (Ridder et al. 2018), and precipitation (Lavers et al. 2010; Lavers and Villarini 2013; Ramos et al. 2015).

Both climate change and natural variability can play a role in changing the nature of extreme precipitation. Synoptic scale features, such as ARs, have a well-established influence on regional precipitation extremes (Lavers et al. 2010; Lavers and Villarini 2013; Ramos et al. 2015). The link between extreme Norwegian precipitation and atmospheric rivers is clear from the observational record (Benedict et al. 2019). Azad and Sorteberg (2017) show that $55-58$ of the extreme 'daily precipitation events' (defined as days where $10-20$ stations have precipitation $>99.5 \%$ ) that occurred between 1900-2009 were associated with 
ARs, and that most of these events occurred in November, December and January (Azad and Sorteberg 2017). It has been demonstrated that in most years 1-2 AR events contribute $30-40 \%$ of the total winter snow pack (snow water equivalent) on the west coast of North America (Guan et al. 2010). Although it is located much further north, the Norwegian west coast has a similar geography with a westerly flow directed over a large mountain range, and it is clear that ARs have a large influence on Norwegian precipitation (Azad and Sorteberg 2017).

Global climate model studies indicate that the total wetday precipitation, the number of heavy precipitation days per year, and the number of very wet days all increase in northern Europe by 2081-2100, under RCP8.5 (Sillmann et al. 2013; Seneviratne et al. 2012; Collins et al. 2013). Further, there is a significant increase in the winter maximum five-day rainfall amounts in northern Europe (Sillmann et al. 2013). It is generally accepted that such projected increases in precipitation are associated with the increased water holding capacity of a warmer atmosphere (Held and Soden 2006).

Several papers have examined projected changes in ARs in North America (Gao et al. 2015; Payne and Magnusdottir 2015; Gershunov et al. 2019), British Columbia (Radic et al. 2015), the Iberian Peninsula (Ramos et al. 2015), Britain (Lavers et al. 2013), and Europe, including Norway (Gao et al. 2016), and globally Massoud et al. (2019) and Espinoza et al. (2018). It has been established that CMIP5 models, including EC-Earth, can simulate the statistics of ARs well (Radic et al. 2015; Gao et al. 2015; Ramos et al. 2016). Indeed, it is projected that there will be an increase in number and intensity of AR days under RCP8.5 (Ramos et al. 2016; Gao et al. 2015), and that the number of ARs reaching Europe will double by 2074-2099 (RCP8.5) (Ramos et al. 2016). It has been shown that most of the AR frequency increase is driven by thermodynamic changes (Gao et al. 2015; Radic et al. 2015), but dynamic changes, such as changes in winds associated with a shift in the mid-latitude jet, also play a small role for North America (Gao et al. 2015; Shields and Kiehl 2016).

The moisture in ARs is generally associated with extratropical cyclones (in the warm core and the trailing cold front) (see Stohl et al. 2008), and references within). While it is commonly thought that ARs have only tropical moisture sources, it has been shown that local, non-tropical sources of moisture make a substantial contribution to the precipitation that reaches Norway (Stohl et al. 2008), through the continuous cycling of moisture within the cyclone (Dacre et al. 2015). In an extra-tropical cyclone, the cold front moves towards the warm front causing a narrowing of the warm sector and a band of high water vapor along the cold front (Sodemann and Stohl 2013; Dacre et al. 2015). This view highlights the importance of extra-tropical cyclones for the moisture transport and precipitation associated with ARs.

The use of a high-resolution global climate model was considered an essential part of this research for several reasons. First, it is generally accepted that high horizontal resolution is necessary for the simulation of extreme events, particularly for precipitation. Second, it is well known that ARs interact with local topography to produce extreme precipitation amounts. It follows that a model must realistically represent the topography for the accurate simulation of AR-related precipitation. There is a substantial difference in the largest mountains in Norway in the low-resolution version of EC-Earth used in the CMIP5 experiment (1118 m), compared to the high-resolution model used in this study $(1582 \mathrm{~m})$. Third, high resolution is necessary to simulate well the small-scale sharp frontal structures that are associated with AR development. This is demonstrated by Zappa et al. (2013), who showed that CMIP5 models, including EC-Earth, with higher horizontal resolution have a better simulation of the cyclone number and intensity, and the storm-track position and orientation than those models with a lower spatial resolution.

It is important to study the relationship between AR variability and extreme precipitation, and future changes in AR themselves. Both of these features will likely influence ARinduced precipitation in Norway. This will be one focus of the current study. In addition to examining changes in AR over time, we use extreme value theory to model the relationships between ARs and extreme precipitation in Norway. This framework has been used previously to model the relationships between soil moisture and extreme European maximum temperatures (Whan et al. 2015a), El Nino-Southern Oscillation and extreme precipitation in North America (Zhang et al. 2010; Cannon 2015; Whan and Zwiers 2016), and atmospheric blocking and extreme minimum temperatures (Sillmann et al. 2011; Whan et al. 2015b). The next section will outline the data sets and methods used in the study, followed by results, discussion and conclusions.

\section{Data and methods}

\subsection{EC-Earth and observations}

We use global climate model simulations from EC-Earth with the same model setup as in (Haarsma et al. 2013). The horizontal resolution is T799 L91 $(\sim 25 \mathrm{~km})$. We use six ensemble members of 5 years from four periods: Past (1850-854), Current (2002-2006), Near-Future (2030-2034) and Far-Future (2094-2098). This results in 30 independent years per period. Longer runs that span a larger range of the natural variability would be desirable but are computationally expensive and not feasible. These years 
were chosen to include the dominant modes of climate variability Haarsma et al. (2013), but it is unlikely that the full range of variability can be sampled with such a modeling set up. The future simulations (Near-Future and Far-Future) are based on the RCP 4.5 scenario (van Vuuren et al. 2011). The six member ensemble was generated by taking one of the first 6 days of October from the previous year as the initial conditions and running the model forward until 1 January. The spin up period is then discarded. This method resulted in sufficient spread in the ensemble that the members can be treated as independent after January 1. See Haarsma et al. (2013) for more details on the model setup.

From EC-Earth, we also use precipitation, $2 \mathrm{~m}$ temperature and specific humidity, as well as vertically integrated water vapor transport (IVT) in EC-Earth and ERA-Interim (as observations), and use this to define observed atmospheric rivers (see the next section for details on this procedure). The horizontal resolution of ERA-Interim $\left(\sim 0.75^{\circ}\right.$, Dee et al. 2011), is much coarser than that of EC-Earth.

In both EC-Earth and ERA-Interim, IVT is calculated from the vertical integral of specific humidity $(Q)$, and the $U$ and $V$ components of wind across five levels between 850 and $200 \mathrm{hPa}$, as well as surface pressure $(p)$ and the acceleration due to gravity $(g)$. We are constrained by the available model levels in EC-Earth. We calculate IVT as follows (Eq. 1):

$$
I V T=\sqrt{\left(\frac{1}{g} \int_{850}^{200} Q U d p\right)^{2}+\left(\frac{1}{g} \int_{850}^{200} Q V d p\right)^{2}} .
$$

We use precipitation observations from seNorge2, a $1 \mathrm{~km}$ gridded dataset for Norway (Lussana et al. 2018). In the observations and in each period in EC-Earth, we calculate the extended winter (October-March) maximum precipitation at each grid cell. We define two regions where AR have a large impact on precipitation; the mid-West Coast (mWC) and south-West Coast (sWC). The $\mathrm{mWC}$ is a polygon contained in the region: $9^{\circ} \mathrm{E}-18^{\circ} \mathrm{E}$ and $64^{\circ} \mathrm{N}-69.5^{\circ} \mathrm{N}$. sWC is a square with the extent: $4^{\circ} \mathrm{E}-7.5^{\circ} \mathrm{E}$ and $57.8^{\circ} \mathrm{N}-63^{\circ} \mathrm{N}$ (Fig. 1b).

\subsection{Atmospheric river definition}

We use an automatic atmospheric river detection algorithm to define atmospheric rivers from 6-h integrated water vapor transport (Lavers and Villarini 2013; Lavers et al. 2013; Gao et al. 2016). The back-tracking algorithm that we use is different to other object oriented or geometric approaches (Sellars et al. 2015; Guan and Waliser 2015), but it has been shown that there is high-agreement between the back-tracking and object oriented methods (Guan and Waliser 2015). The back-tracking algorithms are based on IVT exceedances above a certain threshold, the choice of threshold is critical.
A low threshold will result in too many days being classified as AR-days, while a high threshold will exclude all but the strongest events. It is common practice to calculate the IVT thresholds relative to the model's own climatology (Warner et al. 2014). The comparison between different time periods can use either (1) a varying IVT threshold for each period, which will show how the most extreme events of each period change, and (2) a fixed IVT threshold for all periods, which shows the relative changes in AR events.

First, we define a variable IVT threshold in each data set (ERA-Interim and EC-EARTH) and period (Past, Current, Near-Future, Far-Future). For this threshold, we take the $95 \%$ percentile of IVT along the Norwegian coast, from 58 to $67^{\circ} \mathrm{N}$ (purple dots in Fig. 1). The selected thresholds can be seen in (Fig. 1). It is clear that IVT increases from the Past to the Far-Future in EC-EARTH, from 347 to $478 \mathrm{~kg} / \mathrm{m} / \mathrm{s}$. The selected thresholds in ERA-Interim using all years (1980-2016) is somewhat lower than the current period in EC-EARTH. Restricting ERA-Interim to the same years reduces the discrepancy somewhat. Remaining differences are likely due to differences in horizontal resolution. This threshold is similar to that used previously (Ramos et al. 2015, 2016). Next, we calculate AR events from a fixed IVT threshold, which allows us to examine changes compared to a fixed climate period, similarly to (Warner et al. 2014). Here we use the $95 \%$ percentile of the current period IVT $(368 \mathrm{~kg} / \mathrm{m} / \mathrm{s})$

Second, at each time step we search the grid boxes along the Norwegian coast to find cases where the AR IVT exceeds the IVT threshold (fixed or variable). If the maximum coastal IVT value exceeds the threshold, we trace backwards and find the largest adjacent IVT values, until the path of consecutive grid cells that exceeds the IVT threshold is longer than $2000 \mathrm{~km}$. An example of this from ERA-Interim can be seen in Fig. 1. Finally, we ensure that the AR event is of sufficient length, by only retaining AR events that last for at least three time steps $(18 \mathrm{~h})$. This definition means that there is at least 6-h between AR events, which is shorter than some other definitions such as Lavers and Villarini (2015) who consider AR events as distinct if they are separated by 24 $\mathrm{h}$. While our definition is somewhat less strict, it likely still distinguishes between different storm events in most cases.

From this set of AR events, we can define two indices; (1) AR intensity, that is the average IVT at landfall, and (2) AR frequency, that is the average number of AR events that occur each time period.

\subsection{Generalised extreme value distribution}

We use a generalized extreme value (GEV) distribution (Coles 2001) to assess the relationship between extreme precipitation and covariates (i.e. AR intensity and specific humidity). The GEV describes the behavior of block 
(a)

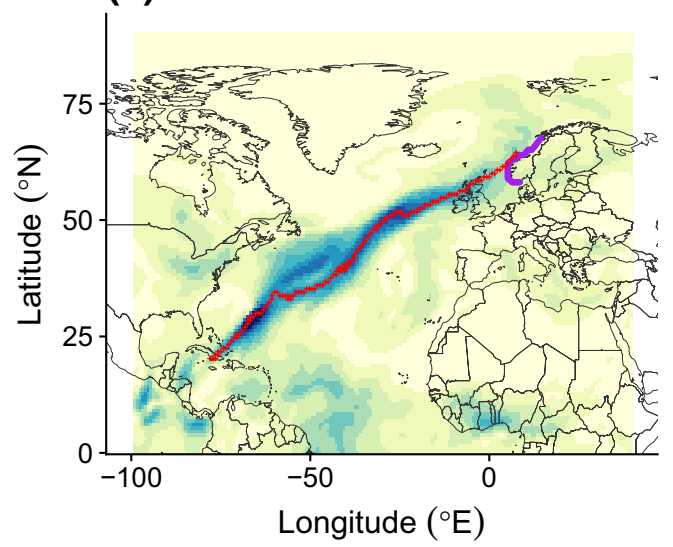

(b)

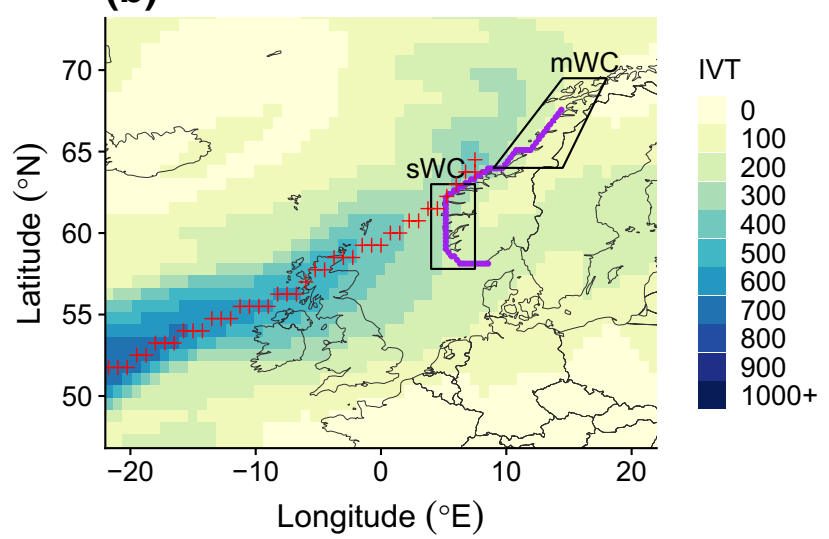

(c)

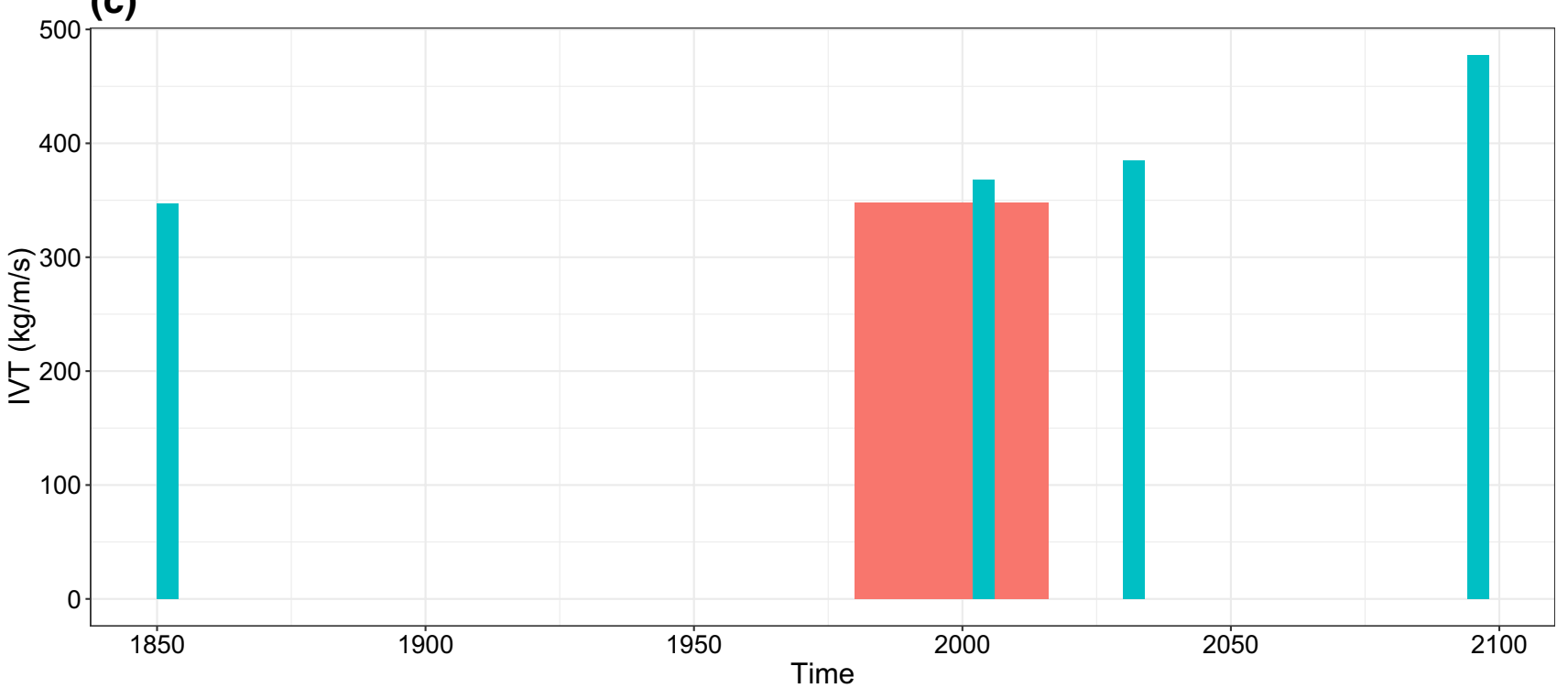

ERA-Interim EC-EARTH

Fig. 1 a IVT at 0000 UTC on October 26, 2014 from ERA-Interim for the North Atlantic region. The purple dots indicate the coastal coordinates used to detect time steps where the IVT exceeds the threshold. The red crosses show the grid cells retained in the tracking algorithm that are used to define an AR time step. b Same as a,

maxima, and so we fit the GEV to the winter (October-March) maximum of daily regional mean precipitation. The GEV is described by three parameters, the location parameter $(\mu)$, the scale parameter $(\sigma)$, and the shape parameter $(v)$. The cumulative distribution function is shown in (Eq. 2):

$G(x)=\exp \left[-\left(1+v\left(\frac{x-\mu}{\sigma}\right)\right)^{(-1 / v)}\right]$.

We fit stationary models (i.e. models with no covariates, M0) to each period separately, and we also pool data across but focused on the Norwegian region, and showing the mid-West Coast (mWC) and south-West Coast (sWC) regions. c IVT thresholds $(\mathrm{kg} / \mathrm{m} / \mathrm{s})$ for each period $($ Past $=1850-1854$; Current $=2002-2006$; Near-Future $=2030-2034$; Far-Future $=2094-2098)$ in EC-Earth (blue) and ERA-Interim (1979-2016; red)

periods to increases the sample size. Pooling data results in a total sample size of 120 (i.e. 6 ensemble members $\times$ 4 periods $\times 5$ years per period). The larger sample size is necessary in fitting the additional parameters in the nonstationary models. In these models, we allow either only the location parameter to vary linearly with one covariate $(M 1)$, or both the location and scale parameters to vary with one covariate (M2). Equation (3) shows how $\mu$ depends linearly on a single covariate, $z$. We test the significance of including additional covariates in nested models, using a likelihood ratio test (LRT). We indicate below in which statistical 
models the inclusion of additional covariates significantly improves model fit $(p<0.1)$.

$\mu(z)=\beta_{0}+\beta_{1} z$.

The covariates that we use are the maximum AR intensity (defined using the fixed threshold) and specific humidity. We use IVT to define ARs. IVT is calculated based on specific humidity, winds and surface pressure. We fit models using specific humidity from the AR as a covariate in an attempt to shed light on whether the influence of AR events stems solely from thermodynamic changes, which can be represented by variability in specific humidity. We detrend the covariate data by removing the period mean and dividing by the period standard deviation. We detrend precipitation data by scaling by the region mean precipitation.

We then calculate the 20-year return values of the stationary model and for non-stationary models when the covariates are low and high (i.e. at the 1st and 99th percentiles). This return value is then the magnitude of the 1-in-20 year extreme event that we can expect when the covariate is in a particular state. Confidence intervals are calculated around this return value using the normal approximation (the delta method) in the 'extRemes' package in R (Gilleland and Katz 2016). More information on this method can be found in Coles (2001). We simulate the expected precipitation given a particular regime of the covariate by taking one thousand random draws from GEV distributions with the GEV parameters adjusted for high (99th percentile) and low (1st percentile) values of the covariate. From this we are able to reproduce the expected probability density function of precipitation, given a particular value of the covariate. All extreme value analysis uses the package 'extRemes' (Gilleland and Katz 2016) from the R statistical computing environment ( $\mathrm{R}$ Core Team 2019).

\section{Results}

\subsection{Model evaluation}

We first evaluate the simulation of AR events in the current period of EC-Earth compared to ERA-Interim. There is a similar average number of AR events per year in ERAInterim and the current period in EC-Earth (Fig. 2a). Both ERA-Interim and the current period of EC-Earth have more AR events occurring in winter compared to summer. The annual cycle of AR frequency is well captured by EC-Earth compared to ERA-Interim, with most events occurring in September-January (Fig. 3).

The intensity of AR events in the current period of ECEarth is somewhat higher than in ERA-Interim, particularly

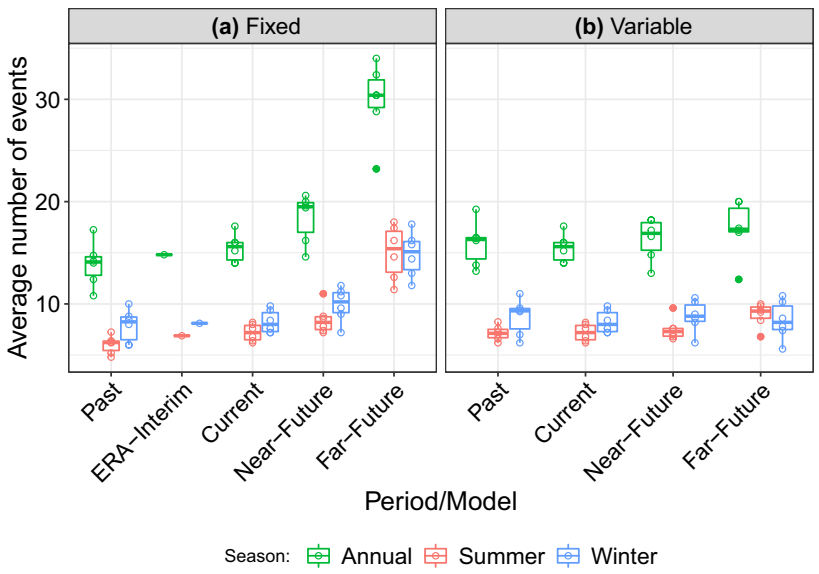

Fig. 2 Average number of AR events per year (green) and season (winter = blue; summer = red), with a fixed (left) or variable (right) IVT threshold. Open circles indicate individual ensemble members. Boxplots show the variability between ensemble members. Filled circles indicate members that are outliers in the boxplot

(a) Fixed threshold

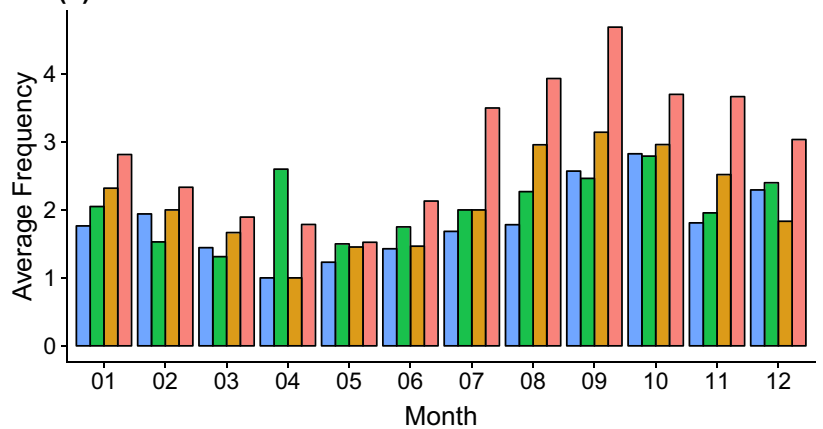

(b) Variable threshold

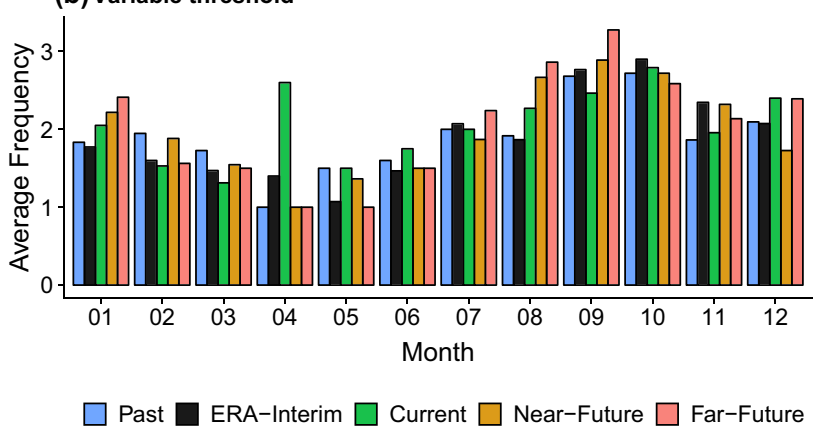

Fig. 3 The number of AR events in each month, calculated using a a fixed, or b variable IVT threshold, in ERA-Interim (black) and each period in EC-Earth $($ Past $=$ blue; Current $=$ green; Near-Future $=$ orange; Far-Future $=$ red)

in summer (Fig. 4). This is due to the lower values associated with the 95th percentile in EC-Earth versus ERAInterim, which is likely due to the fact that the ERA-Interim data set spans a longer time period (1979-2016) and has a lower horizontal resolution. 


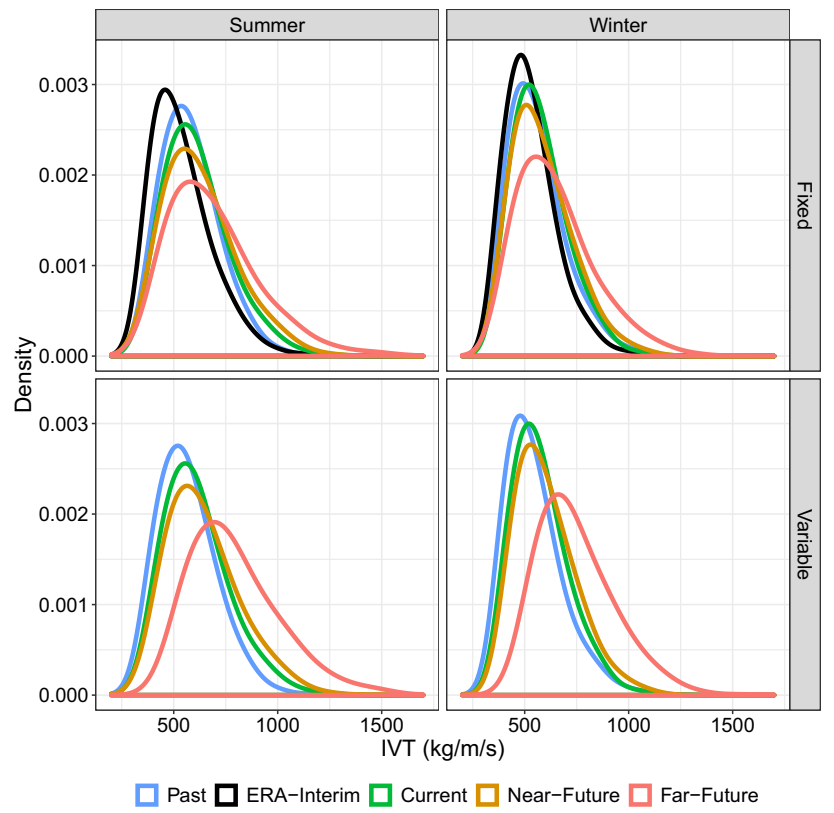

Fig. 4 The distribution of mean AR intensity at landfall in summer (left) and winter (right) using a fixed (top) and variable (bottom) IVT threshold. ERA-Interim = black; Past $=$ blue; Current $=$ green; NearFuture $=$ orange $;$ Far-Future $=$ red

To assess the influence of AR events on winter precipitation extremes, we find the winter precipitation maxima at each grid cell, and then calculate the percentage of winter precipitation maxima that are associated with AR events. The spatial pattern of AR influence is well captured by EC-Earth. In both the model and observations, two regions become clearly evident where a large fraction of winter precipitation maxima are associated with AR events (mid-West Coast, mWC, and south-West Coast, sWC; Fig. 5). In these regions, up to $95 \%$ of winter precipitation extremes are associated with AR events. There is not always a linear increase from the Past period to the Far-Future period, indicating that variability is evident in both regions but particularly in the $\mathrm{mWC}$. This is expected given the highly variable nature of precipitation on inter-annual and inter-decadal scales. We can compute the Perkin's Skill Score (PSS) to compare the similarity between two density functions (Perkins et al. 2007), in this case the distribution of regional precipitation in EC-Earth and ERA-Interim. The PSS for the observations and the Past EC-Earth simulation on the $\mathrm{mWC}$ is 0.83 , suggesting that the distributions are quite similar (where 1 is perfectly similar, and 0 is completely different) despite differences in the resolution. Overall, the precipitation patterns and the fraction of extremes associated with ARs are both well simulated by EC-Earth.

Finally, we compare the region-mean winter precipitation maxima. To do this, we take the winter maxima at each grid cell and then average over all grid cells in the region (sWC,
$\mathrm{mWC}$ ). The magnitude of region-mean winter maximum precipitation in the current period of EC-Earth is comparable to ERA-Interim, as ERA-Interim lies within the ensemble spread, although the ensemble mean is slightly slower than ERA-Interim (Fig. 6).

\subsection{Future changes in atmospheric rivers}

We examine changes in the frequency of AR events using two IVT thresholds; a threshold that is fixed to the current climate, and a variable threshold that is specific to each time period. Using the current climate as a reference, Fig. 2a shows a substantial increase in the number of AR events annually, and in both winter and summer, during the FarFuture period. This is expected given a warmer atmosphere that holds more water, and so higher IVT can be expected given an increase in the specific humidity. Indeed both the mean and maximum values of temperature and specific humidity increase from the Past to the Far-Future (Table 1). If AR events are defined using a variable IVT threshold, there is a small increase in the number of events per year in the Far-Future period, but this increase is driven mostly by the increased number of AR events in summer. Indeed, an increase in summer AR events is evident using both IVT thresholds (Fig. 2a, b).

In ERA-Interim, and the Past, Current and Near-Future periods of EC-Earth, there are more AR events in winter than in summer. However, in the Far-Future period, the seasonal differences are reduced, and there are an equal number of AR events in winter and summer (Fig. 2a, b). The increased number of AR events in the Far-Future using a variable IVT threshold is primarily driven by increases in July-September (Fig. 3b). The summer increase in the FarFuture period using a fixed IVT threshold is evident in all months except May, but is particularly large in July-September (Fig. 3a).

In addition to becoming more frequent in the Far-Future, AR events are more intense, regardless of the IVT threshold used to define AR events. This result is robust across AR the two IVT threshold types tested here (fixed and variable) and is evident in both summer and winter, as we see in Fig. 4 that the probability density function for the FarFuture shifts to the right. The increase in AR intensity is larger in the Far-Future with a variable IVT threshold as the threshold is higher and there are thus fewer low IVT values included. However, even with a fixed threshold there is a marked increase in the intensity in the Far-Future (Fig. 4).

\subsection{Extreme precipitation and atmospheric rivers}

The percentage of winter precipitation extremes that are associated with AR events is relatively steady for the Past, Current and Near-Future periods. This faction increases 
substantially in the Far-Future period (Fig. 5). For the $\mathrm{sWC}$, the regional mean percentage of winter maxima that co-occur with an AR events increases from $\sim 78 \%$ in the Past, Current and Near-Future periods, to $83 \%$ in the Far-Future, with over $90 \%$ of precipitation winter maxima associated with AR events at many locations. On the $\mathrm{mWC}$, the region-mean increase is more substantial, with an increase from around 55\% of winter maxima associated with ARs in the Past, Current and Near-Future periods, to $75 \%$ in the Far-Future (Fig. 5). Overall, it is clear that a larger fraction of regional-mean precipitation events are associated with ARs in the Far-Future.

There are few changes in the magnitude of the regionmean winter precipitation maxima from the Past to the Near-Future periods, and it is only in the Far-Future that we see a substantial increase in the precipitation amounts. The region-mean winter maxima is around $35 \mathrm{~mm} /$ day in the $\mathrm{mWC}$ and around $55 \mathrm{~mm} /$ day in the sWC in the Past, Current and Near-Future periods. There is an increase in the Far-Future period, particularly in the sWC. For the mWC there is a small increase from the Near-Future to the Far-Future periods but the difference is likely not significant (Fig. 6).

Fitting the stationary models to each period separately shows that precipitation extremes are larger in magnitude on the sWC (the 1 -in-20 year return value is $\sim 75 \mathrm{~mm} /$ day), compared to the $\mathrm{mWC}$ (where the 1-in-20 year return value is $\sim 45 \mathrm{~mm} /$ day). There is a small increase in the magnitude of the 1-in-20 year extreme event in the Far-Future period, so that it is expected that a region mean value of $\sim 80 \mathrm{~mm} /$ day would fall once every 20 years (Fig. 7a). This increase is consistent with the increase in precipitation shown in Fig. 6. The 95\% confidence intervals around these estimates are wide, particularly in the Past period, and they are generally overlapping. This is likely due to the small sample size $(\mathrm{n}=$ 30) used when fitting to each period separately.

Next, we explore the influence of covariates (AR and Q) on extreme precipitation in a non-stationary GEV model. Ideally we would fit the non-stationary GEV models to a high-resolution continuous time series, but, unfortunately, no such series is currently available. We pool data over the four distinct periods (Past to Far-Future) to increase the sample size.

In the pooled data set, the magnitude of the 1-in-20 year extreme event is $76 \mathrm{~mm} /$ day on the sWC and $44 \mathrm{~mm} /$ day on the mWC (stationary model in Fig. 7b). This means that we can expect an extreme rainfall event of this size, on average, once in every 20 years. The non-stationary analysis shows the influence of the following covariates on the magnitude of extreme events; the maximum AR intensity and specific humidity $(\mathrm{Q})$. For both regions, increases in the covariates (more specific humidity or a more intense AR) are associated with larger extreme precipitation events. This means that the extreme event that is expected to occur once in 20 years is of a larger magnitude when Q or AR intensity are high, compared to when they are low.

High values of AR intensity (i.e. an intense AR event) and specific humidity both result in an extreme event that is substantially larger than the extreme event that could be expected with a weak AR event. For example, the 1-in-20 year extreme event for the sWC is a region-mean precipitation amount of $>80 \mathrm{~mm} /$ day when AR are intense, compared to $<70 \mathrm{~mm} /$ day when ARs are weak. Both covariates result in a $20-23 \%$ increase in the magnitude than the 20 -year return value. There are few differences in the mean estimates of the 20-year return values from models using these two covariates.

It is well known that a warmer atmosphere has a higher water holding capacity, and that this results in higher atmospheric humidity and precipitation (Byrne and O'Gorman 2018). Use of the raw data where both the covariates and precipitation contain trends will likely artificially increase the strength of the relationship. Due to the trend, the strongest AR events tend to be found in the Far-Future period, but not all strong events are exclusively in this period. Indeed, only half the AR events that exceed the 95th percentile of the current period's IVT distribution are found in the Far-Future period, with the most intense AR events in the other periods also exceeding this percentile. To test the robustness of these results, we next remove the trend in all variables (precipitation, AR intensity and specific humidity), and fit non-stationary GEV models (Fig. 7c). Once de-trended, we see that there is little separation between the 1-in-20 year extreme events expected when specific humidity is low or high. The confidence intervals are overlapping and there is a less than $4 \%$ difference in the mean estimate. This means that there is no difference in the magnitude of the 1-in-20 year extreme event that can be expected when specific humidity is high or low. The strong and significant influence that AR intensity has on extreme precipitation remains, with around a $17 \%$ increase in the magnitude of the extreme event during an intense AR event, compared to a weak event. This confirms the influence of AR intensity on the magnitude of extreme precipitation events. Variability in extreme precipitation is strongly linked to the intensity of the AR event, as more intense AR events are associated with an increase in the 1-in-20 year return value in both regions. These results suggest that specific humidity cannot explain all the influence that $\mathrm{AR}$ have on extreme precipitation, and suggests that the other variables used to define an AR event (surface pressure and both $\mathrm{u}$ and $\mathrm{v}$ winds) may play an important role.

A covariate, such as AR intensity, can influence the distribution of precipitation in multiple ways. A covariate can result in a shift in the mean, to higher or lower values without influencing the spread of the distribution. On the other hand, a covariate can influence both the mean and the spread 
(a) Observations

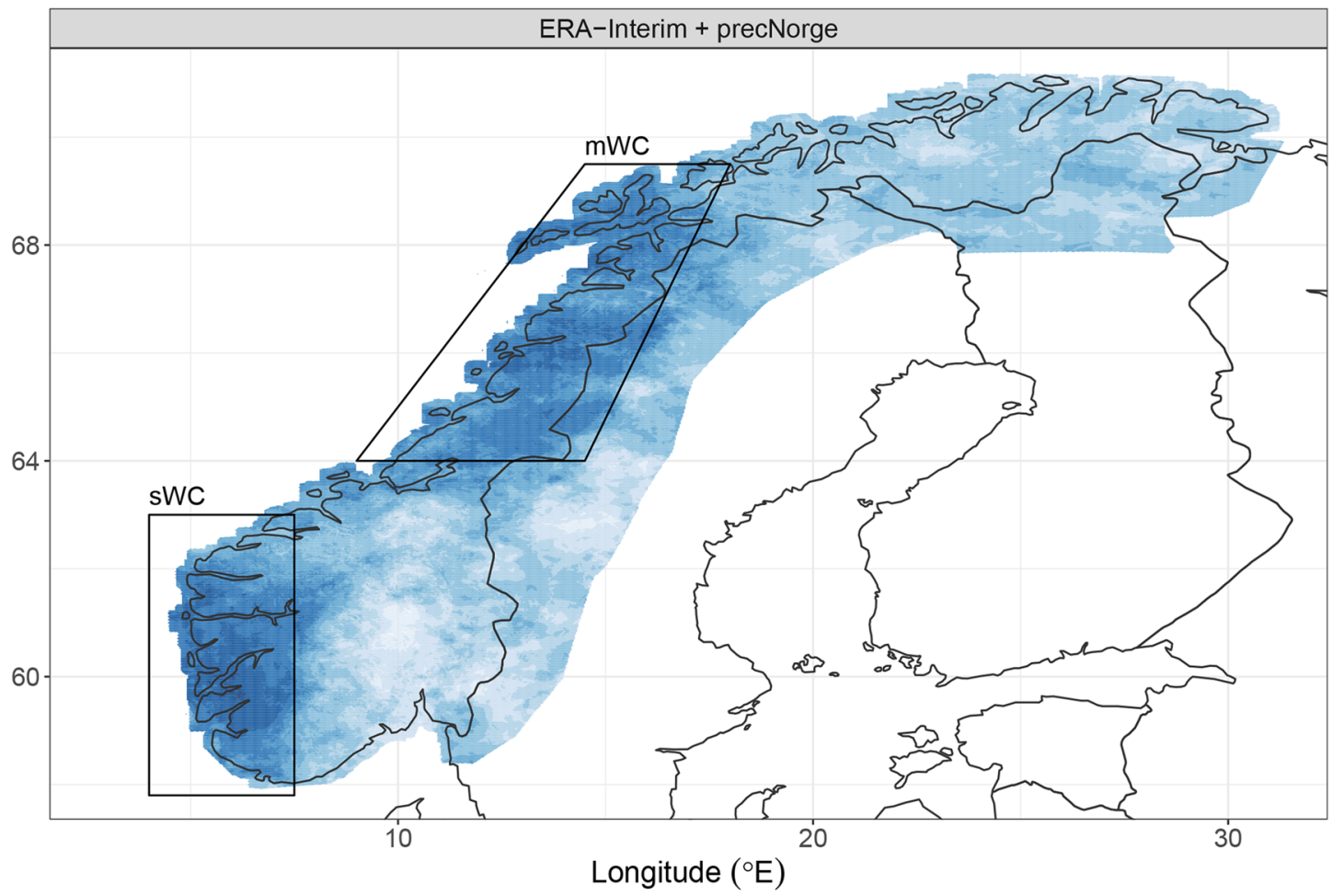

(b) EC-Earth
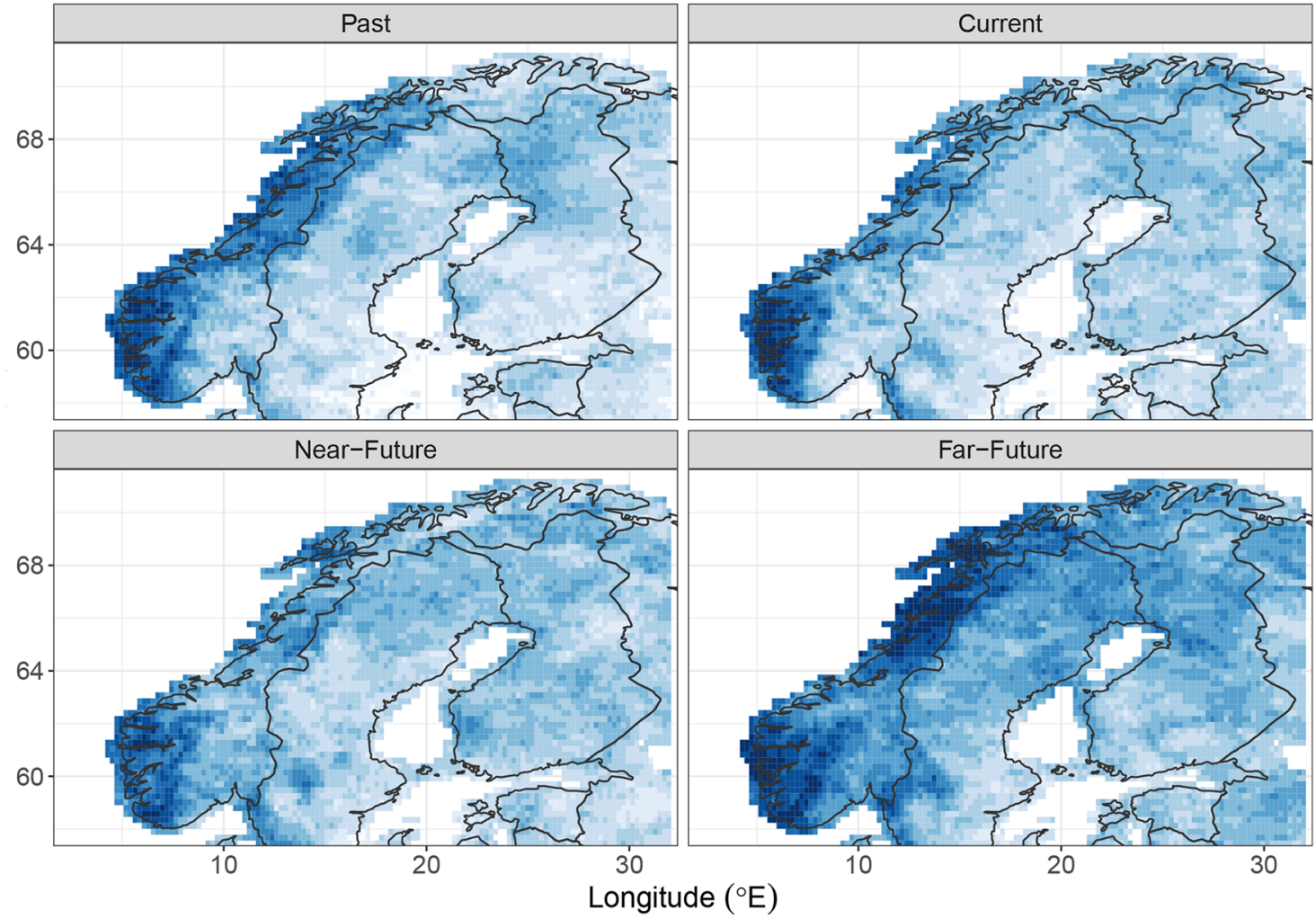

\begin{tabular}{l|l|l|l|l|l|l} 
& {$[0,10]$} & $(20,30]$ & $(40,50]$ & $(60,70]$ & $(80,90]$ \\
\hline & $(10,20]$ & $(30,40]$ & $(50,60]$ & $(70,80]$ & $(90,100]$
\end{tabular} 
4Fig. 5 Percentage of winter maxima precipitation in a observations (ERA-Interim and seNorge2), and b each period in EC-EARTH that are associated with an AR event, defined with fixed threshold. Black lines outline two regions where ARs have a large influence on extreme precipitation; the mid-West Coast (mWC) and the southWest Coast (sWC)

of the distribution, resulting, for example, both a larger mean and spread. These two examples can result in different impacts on society. We fit non-stationary models with covariates on both the location $(\mu)$ and scale $(\sigma)$ parameters (M2 in Fig. 7b) to assess the influence of the covariates on the first two moments of the precipitation distribution. The LRT shows that the M2 model is not significant compared to the M1 model on the mWC. On the sWC the fit of the model is significantly improved by including AR intensity as a covariate on the scale parameter. This suggests that the intensity of an AR event not only shifts the precipitation to larger values (shifting the location parameter), but it also has a significant influence on the spread in the distribution. This effect is evident in (Fig. 8).

We reconstruct the probability density function of mWC and SWC precipitation estimated from GEV parameters that are adjusted according to high and low values of both AR intensity and specific humidity. There is a substantial shift towards high precipitation amounts in both regions when the location parameter is allowed to vary with both specific humidity and AR intensity (Fig. 8, top row, red v blue solid lines), as more intense AR events or high levels of specific humidity are associated with larger precipitation amounts.

The spread of the precipitation distribution can also vary when a covariate is also included in the estimation of the scale parameter (M2). In the sWC, there is a substantial widening of the conditional distribution of precipitation given that AR intensity is high, and a narrowing of the precipitation distribution when AR intensity is low (Fig. 8, bottom row). The distribution of precipitation conditional on specific humidity behaves similarly, but the differences between low and high values of the covariate are not as pronounced.

Finally, we examine the partitioning of extreme winter precipitation between rain and snow. Figure 9 shows the regional mean temperature and the percentage of the region that is below freezing on AR days and non-AR rain days. The sWC is generally warmer than the mWC, as expected. Generally, AR days are warmer and have a smaller fraction of the region that is below zero, than non-AR rain days (Fig. 9). This is consistent with the south-westerly airflow associated with ARs. The increase in regional mean temperature and decrease in the regional freezing fraction is linear from the Past to the Far-Future. In the sWC, the regional mean temperature of AR events in all periods is above zero and less than $50 \%$ of the area is below zero, indicating that precipitation will mostly fall as rain rather than snow. For
non-AR rain days, there is a shift from winter days with sWC regional mean temperatures below zero to those with temperatures above zero in the Far-Future period, and a decrease in the fraction of the region that is below zero. In the mWC, all non-AR rain days have regional mean temperatures below zero and more than half the region is below zero, even in the Far-Future period, indicating that the majority of precipitation would fall as snow. In the Past and current periods, AR events have regional mean temperatures below zero and the majority of the region is below zero, suggesting that most precipitation will fall as snow rather than rain. However, in the Near-Future period, the regional mean temperature fluctuates around the freezing point, while in the Far-Future period, AR events have temperatures above zero with the majority of the region's temperatures above zero. This indicates that by the end of the century, more AR precipitation will be falling as rain rather than snow in the $\mathrm{mWC}$ region.

\section{Discussion and conclusions}

We are interested in the future changes in atmospheric river (AR) events, and on the influence that AR variability has on extreme precipitation. We define a set of AR events from integrated water vapor transport (IVT) in observations (ERA-Interim) and four time-slices in the global climate model, EC-Earth. We verify that the simulation of AR frequency and intensity in EC-Earth is comparable to ERAInterim. We then show that $\mathrm{AR}$ events become more frequent in the future, compared to the present climate, and that the intensity of ARs increases in the future. We identified two regions where ARs have the largest influence on Norwegian precipitation; the mid-West Coast and the south-West Coast.

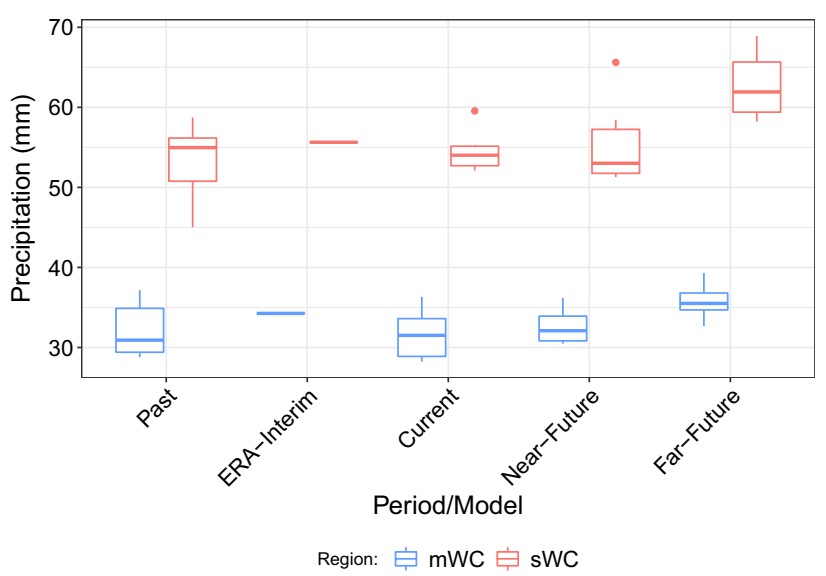

Fig. 6 Region mean of the winter maxima, in ERA-Interim and each period in EC-Earth (Past, Current, Near-Future, Far-Future), for the mWC (blue) and sWC (red). Boxplot shows spread over ensemble members 
Fig. 7 a The 20-year return values (RV20) of the winter maxima in the mid West Coast (mWC, circle) and the south West Coast (sWC, triangle) from the stationary GEV models fit separately to each period. b The RV20 from the stationary and non-stationary GEV models fit to the pooled data in the midWest Coast (mWC, left) and south-West Coast (sWC, right). Covariates in the non-stationary models are specific humidity

(Q) and AR intensity. M1 models have a covariate on the location parameter $(\mu)$. M2 models have a covariate on the location and scale parameters $(\mu+\sigma)$. For the non-stationary models, solid (open) shapes indicate that the extra covariate (does not) significantly improves model fit. c The RV20 from non-stationary models based on de-trended data that use specific humidity (Q) and AR intensity as covariates on the location parameter (a)

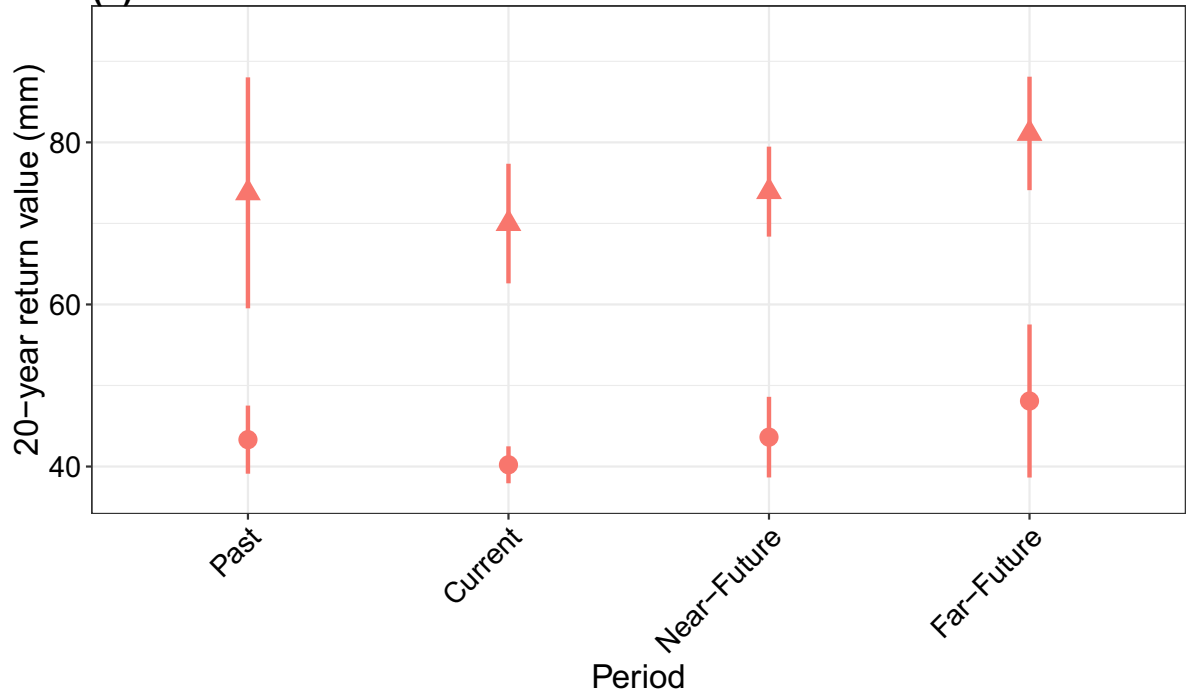

(b)
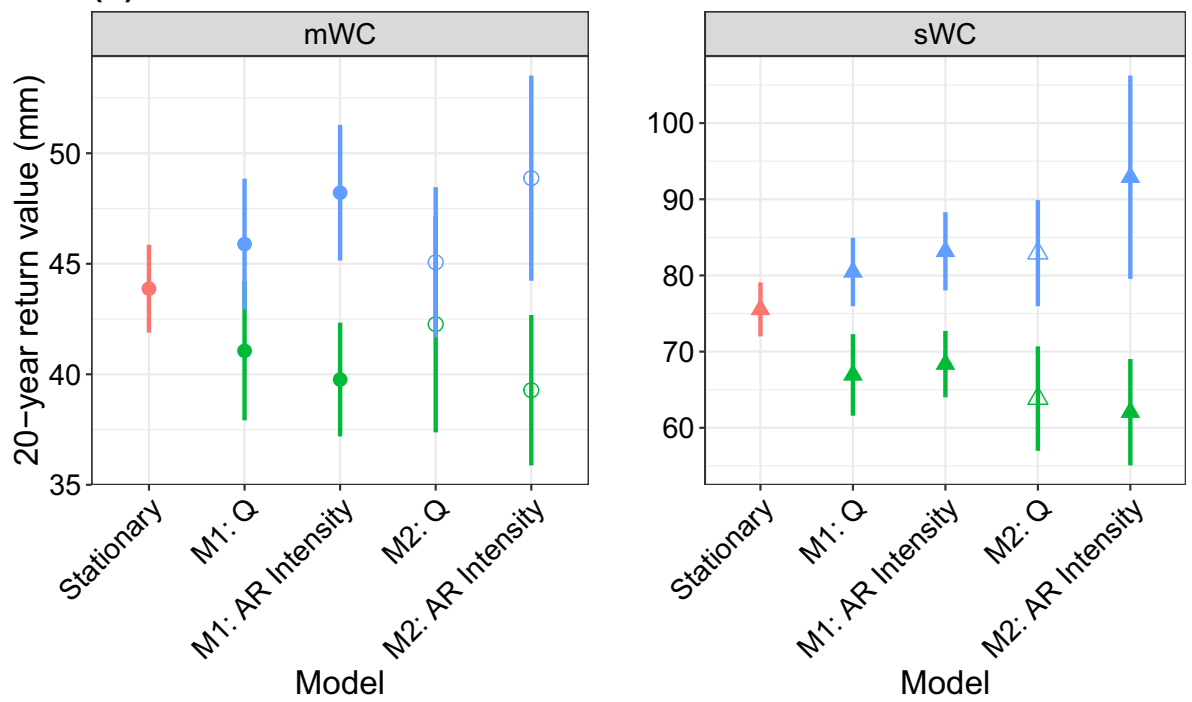

(c)

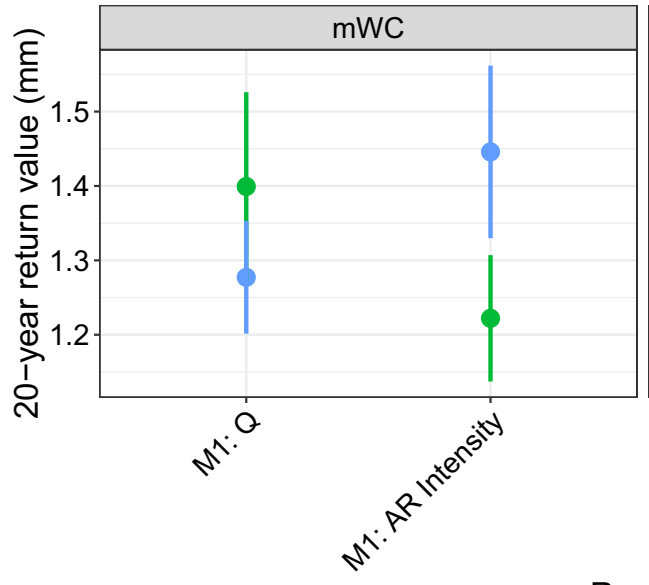

Region

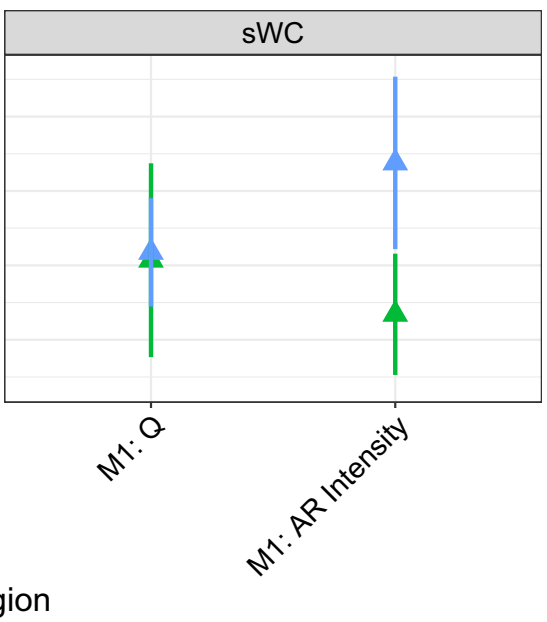

1st -99 th 
Fig. 8 Probability density functions reconstructed from the parameters of the fitted extreme value distributions for each region (mid-West Coast (mWC) $=$ left; south-West Coast (sWC) $=$ right) where the location parameter $(\mu)$, or both the location and scale parameters $(\mu$ $+\sigma)$ are adjusted according to low (blue) and high (red) values of the covariates, AR intensity (solid) and specific humidity (dashed)

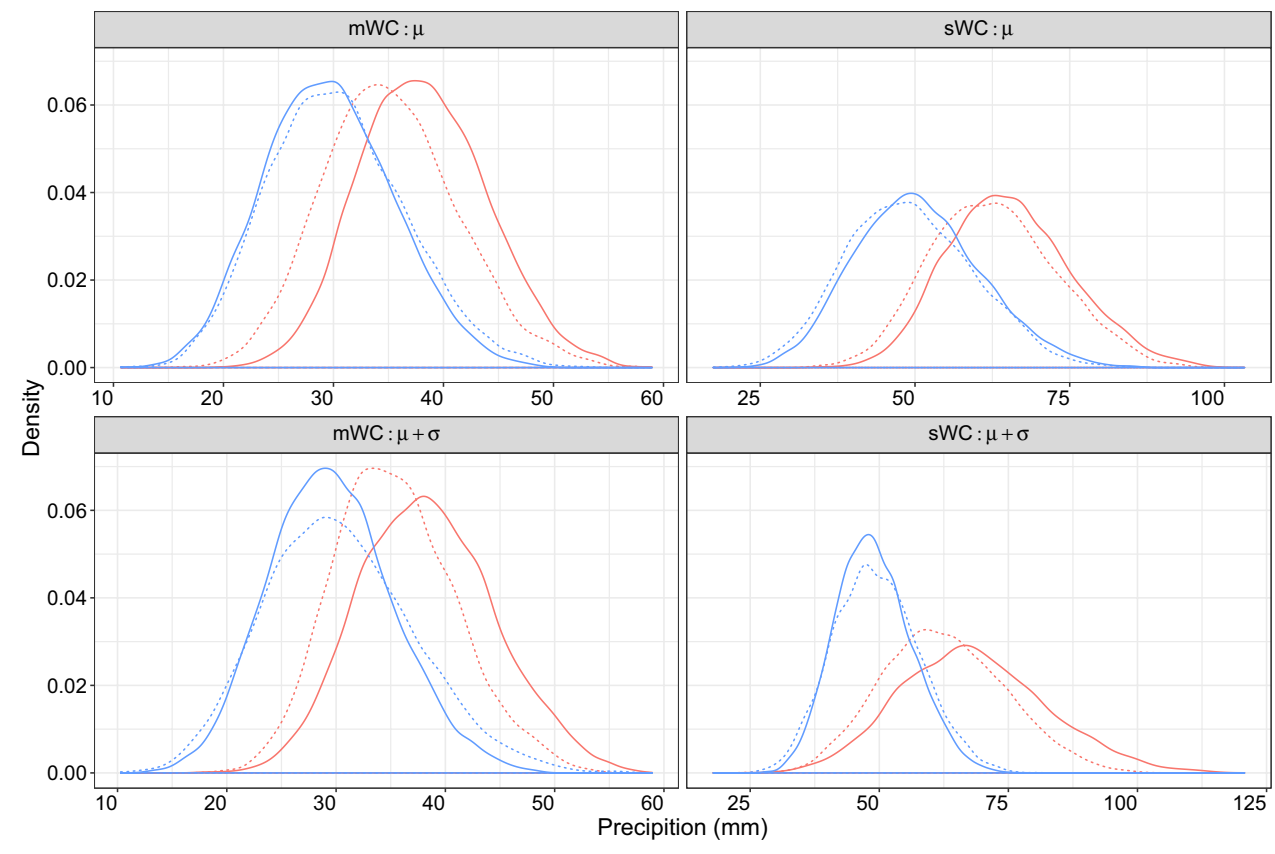

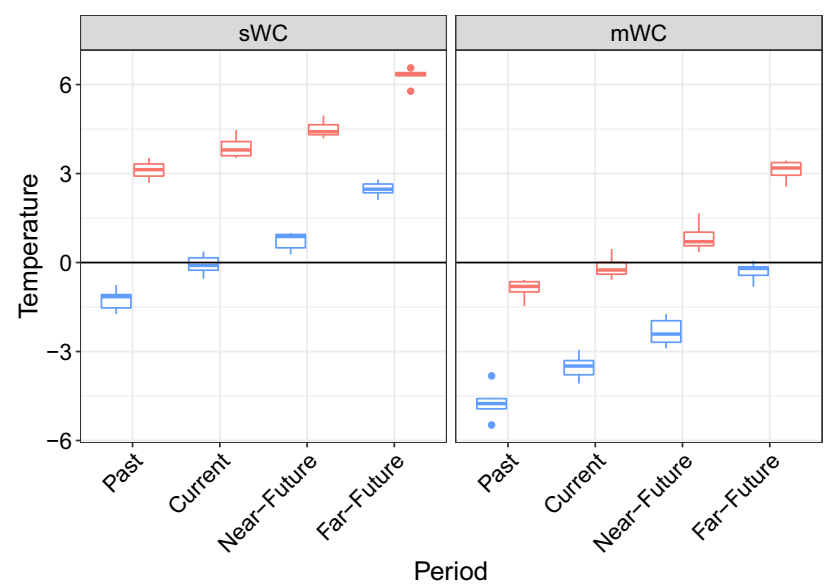

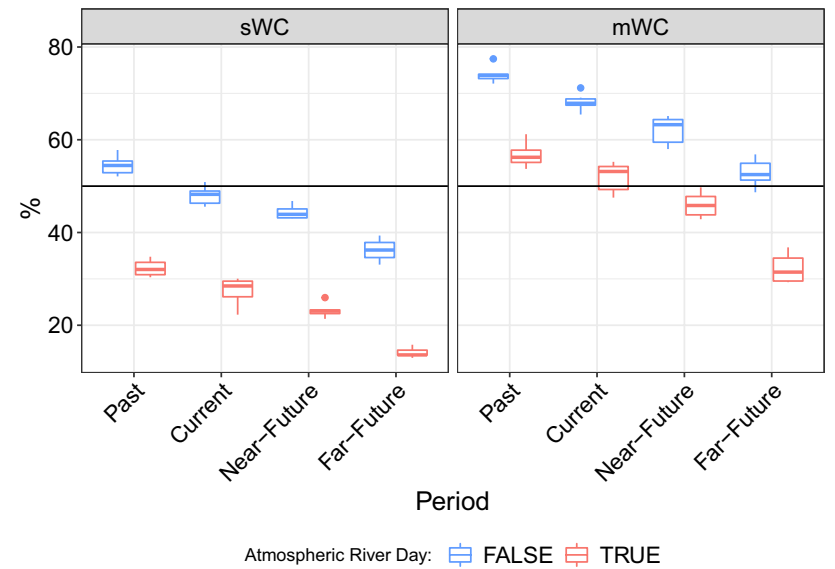

Fig. 9 The region mean EC-Earth $2 \mathrm{~m}$ temperature (top) and the fraction of the region with freezing temperatures (bottom) on atmospheric river days (red) and other rain days (blue) for the sWC (left) and mWC (right) in each period. Boxplot shows spread over ensemble members
Table 1 The average 2-m temperature (T2M) and maximum specific humidity $(\mathrm{Q})$ over the North Atlantic region in each period from ECEarth

\begin{tabular}{lll}
\hline Period & Mean T2M & Maximum Q \\
\hline Past & 12.63 & 0.0096 \\
Current & 13.60 & 0.0101 \\
Near & 14.35 & 0.0107 \\
Future & 16.78 & 0.0126 \\
\hline
\end{tabular}

We examined the influence of AR variability on extreme precipitation by fitting non-stationary generalized extreme value distributions to the region mean winter maxima precipitation. We use either specific humidity or AR intensity as covariates on the location parameter, or on both the location and scale parameters. More intense AR events and higher levels of specific humidity are both associated with around a $20 \%$ increase in the magnitude of extreme events, compared to the 1-in-20 year extreme event that is expected when AR are weak. The influence of AR intensity on precipitation extremes remains after de-trending, while the relationship between specific humidity and precipitation decreases, suggesting that the relationship was spuriously strong due to the trend in both variables. The trend in specific humidity and precipitation stem from the increased water holding capacity of the atmosphere that is caused by global warming (Byrne and O'Gorman 2018).

ARs are defined from IVT, which is a function of specific humidity, surface pressure, and winds (both zonal and meridional). We show that the variability of extreme precipitation is more strongly dependent on AR intensity than 
on only specific humidity, particularly once all variables are de-trended. These differences may indicate the influence of dynamical changes (i.e. a change in the $\mathrm{U}$ and $\mathrm{V}$ components of wind), in addition to the thermodynamic effects. These possible dynamic changes are much more uncertain, given that we examine only one GCM. EC-Earth is one of the best performing models in the historical period in terms of cyclone track position and tilt (Zappa et al. 2013), but of course this does not guarantee good future performance. Future research should focus on untangling the influence of dynamic changes on Norwegian ARs. Multi-model, continuous high-resolution ensemble simulations, such as those being produced in HighResMIP (Haarsma et al. 2016), will provide an opportunity to explore these differences further, but are not all as high-resolution as the version of EC-Earth we have used in this study.

The reconstructed distributions of precipitation conditional on AR intensity shows that the distribution of precipitation shifts to more extreme values when AR or specific humidity intensity is high. There are substantial differences between the distributions of precipitation in the south-West Coast that are conditional on AR intensity and specific humidity, with a more pronounced shift to wetter extremes when AR intensity is high.

The increase in AR events in the Far-Future in late summer and autumn (July-September) is striking. This increase may be related to the projected increase of extra-tropical transitions of hurricanes towards Europe (Haarsma et al. 2013). It is also possible that there is an increase in late summer as the start of the winter storm season combines with warm sea-surface temperatures, which could result in a large increase in water transport. Future research is necessary to further explore these mechanisms.

Additionally, we demonstrate future changes in the partitioning of AR precipitation between rain and snow, with more of the extreme precipitation falling as rain in the future period. This results is not surprising given the well-known projected warming (Collins et al. 2013), but it will have consequences for flood and water management in the future. In the current climate, AR events are known to bring a large fraction of winter precipitation in only a few days per year, which is then captured as snow (Guan et al. 2010). The increased partitioning of precipitation as rain rather than snow will mean that flooding in winter and autumn is more likely, while decreased snow melt in spring can results in reduced flooding. This would result in less snow captured during winter available for power generation during the remainder of the year.

In summary, our results show that by the end of the century, Norway will likely experience more frequent and more intense AR events. We show that extreme precipitation events are larger in magnitude when the AR event is more intense, which will happen more often in the future. Further, most of this extreme precipitation will likely fall as rain rather than snow. These results have severe implications for water resource management in Norway.

One limitation of this study is that we examine changes only in one GCM (EC-Earth) and one representative concentration pathway (RCP 4.5). We are limited in the number of available models and emissions scenarios, as we needed a high-resolution GCM to properly simulate both extreme precipitation and AR events. As more high-resolution global simulations become available (i.e. as part of the PRIMAVERA project), it would be valuable if future work could extend these results using more models and under other RCPs. However, previous work has shown that most of the changes in ARs stem from thermodynamic changes, with a small contribution from dynamic changes (Gao et al. 2015). As EC-Earth performs well in the historical period (Zappa et al. 2013), it is likely that the direction and magnitude of the changes presented here are consistent in other models. The dynamic contribution is more likely to vary between models, and so it would be useful if a more comprehensive study could be conducted in the future. A stronger warming signal under a more aggressive emissions scenario, i.e. RCP 8.5 , would possibly result in a larger increase in ARs, more extreme precipitation, and more precipitation falling as rain rather than snow.

Acknowledgements This study is supported by the TWEX project funded by the Research Council of Norway (Grant \#255037). The authors wish to thank Malte Muller, Harald Sodemann, Kate Saunders, and Trine Hegdahl for useful comments. We also thank the two anonymous reviewers, whose comments have improved the manuscript.

Open Access This article is licensed under a Creative Commons Attribution 4.0 International License, which permits use, sharing, adaptation, distribution and reproduction in any medium or format, as long as you give appropriate credit to the original author(s) and the source, provide a link to the Creative Commons licence, and indicate if changes were made. The images or other third party material in this article are included in the article's Creative Commons licence, unless indicated otherwise in a credit line to the material. If material is not included in the article's Creative Commons licence and your intended use is not permitted by statutory regulation or exceeds the permitted use, you will need to obtain permission directly from the copyright holder. To view a copy of this licence, visit http://creativecommons.org/licenses/by/4.0/.

\section{References}

Azad R, Sorteberg A (2017) Extreme daily precipitation in coastal western Norway and the link to atmospheric rivers. J Geophys Res Atmos 12(4):2080

Benedict I, Ødemark K, Nipen T, Moore R (2019) Large-scale flow patterns associated with extreme precipitation and atmospheric rivers over Norway. Mon Weather Rev 147(4):1415-1428

Byrne MP, O'Gorman PA (2018) Trends in continental temperature and humidity directly linked to ocean warming. PNAS 115(19):4863-4868

Cannon AJ (2015) Revisiting the nonlinear relationship between ENSO and winter extreme station precipitation in North America. Int J Climatol 35:4001-4014 
Coles S (2001) An introduction to statistical modeling of extreme values. Springer, London

Collins M, Knutti R, Arblaster J, Dufresne J-L, Fichefet T, Friedlingstein P, Gao X, Gutowski W, Johns T, Krinner G, Shongwe M, Tebaldi C, Weaver A, Wehner M (2013) Long-term climate change: projections, commitments and irreversibility. In: Stocker T, Qin D, Plattner G-K, Tignor M, Allen S, Boschung J, Nauels A, Xia Y, Bex V, Midgley P (eds) Climate change 2013: the physical science basis. Contribution of Working Group I to the Fifth Assessment Report of the Intergovernmental Panel on Climate Change. Cambridge University Press, Cambridge, pp 1029-1136

Dacre HF, Clark PA, Martinez-Alvarado O, Stringer MA, Lavers DA (2015) How do atmospheric rivers form? Bull Am Meteorol Soc 96(8):1243-1255

Dee DP, Uppala SM, Simmons AJ, Berrisford P, Poli P, Kobayashi S, Andrae U, Balmaseda MA, Balsamo G, Bauer P, Bechtold P, Beljaars ACM, van de Berg L, Bidlot J, Bormann N, Delsol C, Dragani R, Fuentes M, Geer AJ, Haimberger L, Healy SB, Hersbach H, Hólm EV, Isaksen L, Kållberg P, Köhler M, Matricardi M, McNally AP, Monge-Sanz BM, Morcrette J-J, Park B-K, Peubey C, de Rosnay P, Tavolato C, Thépaut J-N, Vitart F (2011) The ERA-Interim reanalysis: configuration and performance of the data assimilation system. Q J R Meteorol Soc 137(656):553-597

Espinoza V, Waliser DE, Guan B, Lavers DA, Ralph FM (2018) Global analysis of climate change projection effects on atmospheric rivers. Geophys Res Lett 45(9):4299-4308

Gao Y, Lu J, Leung LR, Yang Q, Hagos S, Qian Y (2015) Dynamical and thermodynamical modulations on future changes of landfalling atmospheric rivers over western North America. Geophys Res Lett 42:7179

Gao Y, Lu J, Leung LR (2016) Uncertainties in projecting future changes in atmospheric rivers and their impacts on heavy precipitation over Europe. J Clim 29(18):6711-6726

Gershunov A, Shulgina T, Clemesha RES, Guirguis K, Pierce DW, Dettinger MD, Lavers DA, Cayan DR, Polade SD, Kalansky J, Ralph FM (2019) Precipitation regime change in Western North America: the role of atmospheric rivers. Sci Rep 9(1):1-11

Gilleland E, Katz RW (2016) extRemes 2.0: an extreme value analysis package in R. J Stat Softw 72(8):1-39

Guan B, Waliser DE (2015) Detection of atmospheric rivers: evaluation and application of an algorithm for global studies. J Geophys Res Atmos 120(24): 12514

Guan B, Molotch NP, Waliser DE, Fetzer EJ, Neiman PJ (2010) Extreme snowfall events linked to atmospheric rivers and surface air temperature via satellite measurements. Geophys Res Lett 37(20):L20401

Haarsma RJ, Hazeleger W, Severijns C, de Vries H, Sterl A, Bintanja R, van Oldenborgh GJ, van den Brink HW (2013) More hurricanes to hit western Europe due to global warming. Geophys Res Lett 40(9):1783-1788

Haarsma RJ, Roberts MJ, Vidale PL, Senior CA, Bellucci A, Bao Q, Chang P, Corti S, Fučkar NS, Guemas V, Jv Hardenberg, Hazeleger W, Kodama C, Koenigk T, Leung LR, Lu J, Luo J-J, Mao J, Mizielinski MS, Mizuta R, Nobre P, Satoh M, Scoccimarro E, Semmler T, Small J, Storch J-S (2016) High resolution model intercomparison project (HighResMIP v1.0) for CMIP6. Geosci Model Dev 9(11):4185-4208

Held IM, Soden BJ (2006) Robust responses of the hydrological cycle to global warming. J Clim 19(21):5686-5699

Kousky C (2014) Informing climate adaptation: a review of the economic costs of natural disasters. Energy Econ 46:576-592

Langsholt E, Roald LA, Holmqvist E, Fleig A (2015) Flommen på Vestlandet oktober 2014. In: Technical Report Rapport nr 11-2015, NVEs hustrykkeri
Lavers DA, Villarini G (2013) The nexus between atmospheric rivers and extreme precipitation across Europe. Geophys Res Lett 40(12):3259-3264

Lavers DA, Villarini G (2015) The contribution of atmospheric rivers to precipitation in Europe and the United States. J Hydrol 522:382-390

Lavers DA, Villarini G, Allan RP, Wood EF, Wade AJ (2012) The detection of atmospheric rivers in atmospheric reanalyses and their links to British winter floods and the large-scale climatic circulation. J Geophys Res Atmos 117:D20

Lavers DA, Allan RP, Villarini G, Lloyd-Hughes B, Brayshaw DJ, Wade AJ (2013) Future changes in atmospheric rivers and their implications for winter flooding in Britain. Environ Res Lett 8(3):034010

Lussana C, Saloranta T, Skaugen T, Magnusson J, Tveito OE, Andersen $\mathrm{J}$ (2018) seNorge2 daily precipitation, an observational gridded dataset over Norway from 1957 to the present day. Earth Syst Sci Data 10(1):235-249

Massoud EC, Espinoza V, Guan B, Waliser DE (2019) Global climate model ensemble approaches for future projections of atmospheric rivers. Earths Future 7(10):1136-1151

Payne AE, Magnusdottir G (2015) An evaluation of atmospheric rivers over the North Pacific in CMIP5 and their response to warming under RCP 8.5. J Geophys Res Atmos 120(21):11173-11190

Perkins S, Pitman A, Holbrook N, McAneney J (2007) Evaluation of the AR4 climate models' simulated daily maximum temperature, minimum temperature, and precipitation over Australia using probability density functions. J Clim 20:4356-4376

R Core Team (2019) R: A language and environment for statistical computing. R Foundation for Statistical Computing, Vienna, Austria. http://www.R-project.org/

Radic V, Cannon AJ, Menounos B, Gi N (2015) Future changes in autumn atmospheric river events in British Columbia, Canada, as projected by CMIP5 global climate models. J Geophys Res Atmos 120(18):9279

Ramos AM, Trigo RM, Liberato MLR, Tome R (2015) Daily precipitation extreme events in the Iberian Peninsula and its association with atmospheric rivers. J Hydrometeorol 16:579-597

Ramos AM, Tomé R, Trigo RM, Liberato MLR, Pinto JG (2016) Projected changes in atmospheric rivers affecting Europe in CMIP5 models. Geophys Res Lett 43:9315

Ridder N, De Vries H, Drijfhout S (2018) The role of atmospheric rivers in compound events consisting of heavy precipitation and high storm surges along the Dutch coast. Nat Hazards Earth Syst Sci 18(12):3311-3326

Schaller N, Sillmann J, Müller M, Haarsma R, Hazeleger W, Hegdahl T, Kelder T, van den Oord G, Weerts A, Whan K (2019) The role of spatial and temporal model resolution in a flood event storyline approach in Western Norway. Weather Clim Extremes (submitted)

Sellars SL, Gao X, Sorooshian S (2015) An object-oriented approach to investigate impacts of climate oscillations on precipitation: a Western United States case study. J Hydrometeorol 16(2):830-842

Seneviratne SI, Nicholls N, Easterling D, Goodess, CM Kanae S, Kossin J, Luo J, Marengo J, McInnes K, Rahimi M, Reichstein M, Sorteberg A, Vera C, Zhang X (2012) Change in climate extremes and their impacts on the natural physical environment. In: Technical report, Cambridge University Press, Cambridge, UK and New York, NY, USA, A Special Report of Working Groups I and II of the Intergovernmental Panel on Climate Change 
Shields CA, Kiehl JT (2016) Atmospheric river landfall-latitude changes in future climate simulations. Geophys Res Lett 43(16):8775-8782

Sillmann J, Croci-Maspoli M, Kallache M, Katz RW (2011) Extreme cold winter temperatures in Europe under the influence of North Atlantic atmospheric blocking. J Clim 24(5899-5913):22

Sillmann J, Kharin VV, Zhang X, Zwiers FW, Bronaugh D (2013) Climate extremes indices in the CMIP5 multimodel ensemble: Part 1. Model evaluation in the present climate. J Geophys Res Atmos 118:1716-1733 4

Sodemann H, Stohl A (2013) Moisture origin and meridional transport in atmospheric rivers and their association with multiple cyclones. Mon Weather Rev 141(8):2850-2868

Stohl A, Forster C, Sodemann H (2008) Remote sources of water vapor forming precipitation on the Norwegian west coast at $60^{\circ} \mathrm{N}-\mathrm{a}$ tale of hurricanes and an atmospheric river. J Geophys Res 113(D5):D05102

van Vuuren DP, Edmonds J, Kainuma M, Riahi K, Thomson A, Hibbard K, Hurtt GC, Kram T, Krey V, Lamarque J-F, Masui T, Meinshausen M, Nakicenovic N, Smith SJ, Rose SK (2011) The representative concentration pathways: an overview. Clim Change 109(1):5

Waliser D, Guan B (2017) Extreme winds and precipitation during landfall of atmospheric rivers. Nat Geosci 10(3):179-183
Warner MD, Mass CF, Salathé EP (2014) Changes in winter atmospheric rivers along the North American west coast in CMIP5 climate models. J Hydrometeorol 16(1):118-128

Whan K, Zwiers FW (2016) The impact of ENSO and the NAO on extreme winter precipitation in North America in observations and regional climate models. Clim Dyn 48:1401-1411

Whan K, Zscheischler J, Orth R, Shongwe M, Rahimi M, Asare E, Seneviratne SI (2015a) Impact of soil moisture on extreme maximum temperatures in Europe. Weather Clim Extrem 9:57-67

Whan K, Zwiers FW, Sillmann J (2015b) The influence of atmospheric blocking on extreme winter minimum temperatures in North America. J Clim 29:4361-4381

Zappa G, Shaffrey LC, Hodges KI (2013) The ability of CMIP5 models to simulate North Atlantic extratropical cyclones. J Clim 26(15):5379-5396

Zhang X, Wang J, Zwiers FW, Groisman PY (2010) The influence of large-scale climate variability on winter maximum daily precipitation over North America. J Clim 23(2902-2915):11

Publisher's Note Springer Nature remains neutral with regard to jurisdictional claims in published maps and institutional affiliations. 